\title{
AUFFÜHRUNG E AUFZEICHNUNG: ARTE DA CIÊNCIA?'
}

\author{
Gabriele Brandstetter \\ Universidade Livre de Berlim \\ theater-tanz@fu-berlin.de \\ Tradução de Evelyn Schuler Zea \\ Universidade Federal de Santa Catarina \\ evelynsz@gmail.com
}

Resumo: Presença versus representação, eis a fórmula recorrente na problematização da temática referente a "evento" e "estética" tão debatida no contexto da assim chamada "virada performática" não apenas nos estudos em dança e teatro, mas no campo transdisciplinar dos cultural studies, ciências sociais e outras disciplinas. Essa fórmula chama por outras oposições semânticas e seus respectivos discursos na figura da relação (e trata-se de uma relação paradoxal) entre Aufführung e Aufzeichnung, representação e registro, evento e documentação. Neste artigo busco transpor tais oposições rígidas e sua estrutura hierárquica para uma configuração "suave" da relação entre ambas, refletindo sobre a questão da "arte do evento" no seu duplo sentido teórico e performático: na tensão que se instaura entre evento como arte e no registro como ciência e crítica.

Palavras-chave: Aufführung, Aufzeichnung, re-escrita.

\section{AUFFÜHRUNG AND AUFZEICHNUNG: SCIENCE AS ART?}

\footnotetext{
Abstract: Presence versus representation, so runs the current formula that sums up the complex of questions that cluster around the themes of "event" and "aesthetics", such discussed in the context of the so-called "performative turn" not only in dance and theater studies, but also in
} 
the transdisciplinary field of cultural studies, social sciences and other disciplines. This formula calls for other semantic oppositions and their discourses on the figure of the relationship (and this is a paradoxical relationship) between Aufführung and Aufzeichnung, production and preservation, event and documentation. In this article I seek to overcome such rigid oppositions and their hierarchical structure moving towards a "soft" configuration of the relationship between them, reflecting on the question of the "art of event" in its double theoretical and performative sense, that is to say: in the tension that arises between event as art and preservation as scholarship and criticism.

Keywords: Aufführung, Aufzeichnung, re-scription.

Entre os tópicos de estudos em dança e teatro faz parte falar de performance enquanto Aufführung como um evento efêmero. O tópico do transitório, do fenômeno do fugaz, do irrepetível, do singular, não é tido como inerente à obra de arte enquanto fato, mas ocorre no conjunto e como elemento do acontecer de um tempo-espaço compartilhado por atores e expectadores. Independentemente de seu conteúdo e de sua forma, a performance (e também a arte da performance) demanda pela percepção; ela acontece no horizonte da atenção como experiência da presença, em outras palavras, como "produção de presença” (GUMBRECHT, 2001) ou da "encenação da presença" (SEEL, 2001). Ao mesmo tempo, o discurso sobre performance, evento e "produção de presença" tematiza questões da temporalidade do efêmero, do irrepetível: a ausência presente de performance como evento. Esse discurso é marcado por uma atitude melancólica da perda, no qual se destaca o momento sempre já perdido da performance. Quando a performance é de tal modo enfatizada como constelação complexa que nenhuma memória é capaz de reter isso tem o efeito, a meu ver, de relegar o registro a um plano secundário.

Frente e contrário a isso há um tópico distinto e complementar que frisa a importância do registro enquanto Aufzeichnung: seus meios e suas formas, a fixação na escrita, na imagem e no filme. Conectam-se a ele os discursos e as técnicas culturais da memória, a transcrição, a documentação e o arquivamento. 
Presença versus representação, eis a fórmula recorrente nesta problematização da temática referente a "evento" e "estética", tão debatida no contexto da assim chamada "virada performática" não apenas nos estudos em teatro, mas no campo transdisciplinar dos cultural studies, ciências sociais e outras disciplinas. Essa fórmula sobre presença e representação - ou, nas palavras de Gumbrecht, sobre o entrelaçamento de "cultura da presença e cultura da significação" (GUMBRECHT, 2001) - chama por outras oposições semânticas e seus respectivos discursos na figura da relação (e trata-se de uma relação paradoxal) entre Aufführung e Aufzeichnung, representação e registro, evento e documentação.

No que segue, busco transpor tais oposições rígidas e sua estrutura hierárquica para uma configuração "suave" da relação entre ambas. No entanto, isso significa para mim, lançar outra luz sobre as posições que ocupam tanto arte e ciência, quanto representação e registro, não fazendo uma separação entre ambas, mas impelindo-as numa inversão. Interessa-me pensar a questão da "arte do evento" no seu duplo sentido teórico e performático: na tensão que se instaura entre evento como arte e no registro como ciência e crítica. Tensão que provoca interferências, por exemplo, na questão, em aberto, se um evento não é ele mesmo perceptível como um registro; e se a teoria não é ela mesma capaz de instaurar um cenário performativo.

Para a discussão aqui proposta, farei um recorte a partir das seguintes palavras-chave e hipóteses:

1. O objeto fugaz: Aufführung

2. Nova conjuntura de entendimento?

3. Evidência ou arte da ciência?

4. "Reescrita" ou Aufzeichnung como gesto (com Roland Barthes e Giorgio Agamben)

Subjacente às ideias de acoplamento de Aufführung e Aufzeichnung, de evento e registro, figura uma pressuposição que parece estar dada como conditio sine qua non e que, por isso mesmo, não 
é questionada: a pressuposição que existe a possibilidade de uma tradução fiel. Perante essa pressuposição, é preciso contrapor o seguinte: em todo registro e em toda tradução - que sempre implica uma mudança de meios - sempre ocorre uma transformação. Seja sob a forma de imagem, escrita ou vídeo (é claro que teria que se considerar o potencial de registro de cada uma das mídias de modo diferenciado) - a mudança de meio se inscreve em cada registro, em cada tradução. Refletir sobre isso seria, a meu ver, um momento crucial da própria descrição, postulando que se trata de uma descrição que concebe o registro e a episteme do registro como "arte" (no sentido de techné). A postulação deve decididamente ir mais longe: Deve-se encontrar uma forma de representação que assuma a marcação da mudança de meio (e/ou mídia) e que torna visível a fissura da tradução na transcrição mesma. Seria essa uma forma de articular a "arte do evento" e a prática do registro? Ou um modo de demonstrar o tempus ${ }^{2}$ - o tempo próprio e o espaço próprio do registro - na sua dupla constituição paradoxal? Pois, de um lado há a posterioridade da escrita que confere a todo registro seu modo de temporalidade e interrupção de sequencias temporais; assim ela recebe e mostra seu canal reconstruído, sua permeabilidade, sua incompletude constitutiva. E, por outro lado, há aquilo que eu sugiro chamar de caráter preposicional do registro: preposicional no duplo sentido do termo, ou seja, tanto no sentido temporal - na medida em que o registro e a escrita sempre precedem à performance, dito de outro modo: "performance como pré-escrita" (BORMAN, 2004) -, quanto registro como preposição no sentido de proposta. Uma proposta para aquela re-écriture daquilo a ser registrado, uma re-escrita que nunca cumprirá a sua promessa (proposta no sentido de uma aproximação insistente mas que nunca chega a realizar-se completamente).

Há uma relação de imprecisão entre evento e registro: uma "zona cinza" - para designar essa zona imprecisa com uma metáfora. Como essa zona da imprecisão poderia ser marcada aqui? 
Sugiro interceder oito seções que, de acordo com a afinidade entre teoria e teatro - concebida como a abertura de um Schau-Raum (um espaço para ver e dar a ver) -, instauram uma zona como essa: com a instalação ACHT GRAU (oito cinzas), de Gerhard Richter (cf. RICHTER, 2002).

Seção: 1. Imagem

"Dar a ver".

Ingresso três euros. Na bilheteria, a mulher da caixa nos pergunta se nós estamos bem informados: A exposição abrange apenas uma sala com oito quadros. Ela nos explica que alguns visitantes deixaram a sala, enfurecidos, chegando a exigir a devolução do dinheiro do ingresso. A ver: ACHT GRAU.

\section{O objeto fugaz: Aufführung}

A questão de como tornar o transitório de um evento em um objeto que possa ser transmitido (e se tornar formador de uma tradição) na ciência através da escrita e de diversos sistemas e processos de registro, sempre foi um - talvez até "o" - tema principal nos estudos de artes cênicas. Não se trata apenas de uma questão referente à metodologia, mas de uma questão que toca o cerne deste campo de estudos, na medida em que sua autoconcepção depende crucialmente dos processos e (aparentemente) também do sucesso da produção (re)construída de seu objeto fugaz: a Aufführung. Tendo em vista alguns debates recentes, em particular aqueles que surgiram no contexto transdisciplinar do Projeto de Pesquisa Kulturen des Performativen ("Culturas da Performatividade") em Berlim, abordando questões sobre performance e performatividade, a relação entre presença e representação, entre temporalidade e percepção de tempo visando uma teoria do evento, observamos também que parece surgir novamente uma conjuntura da hermenêutica, no sentido de uma hermenêutica da performance. Compreender e in- 
terpretar parecem ser (de repente novamente) as palavras mágicas de um antigo debate redescoberto. Será?

Seção: 2. Imagem

"Isso não é uma imagem." - ACHT GRAU de Gerhard Richter

- uma instalação, que se move entre gêneros estabelecidos: foto, pintura, escultura, arquitetura.

"Isso é uma imagem?" Imagem da imagem?

Eu escolhi folhas para o retroprojetor, mas também poderia ter escolhido uma reprodução via PowerPoint. Trata-se de pôr em questão: O que podemos ver aqui da possibilidade de uma percepção, tal como ela se instaura $n a$ instalação ACHT GRAU?

Isso reforça a dúvida de que aquilo que vemos corresponde a uma realidade da percepção.

\section{Nova conjuntura de entendimento?}

Irei retomar o debate que acabo de mencionar para ver e pensar a dança - por exemplo, na questão colocada no início da série da Revista Ballettanz ${ }^{3}$ : "How to understand the art of dancing"? (CRAMER, 2003, p. 28) ou "Por que compreender a dança? E como? Deve-se ler livros a respeito?" (WESEMANN, 2003, p. 36). Novamente aparece a oposição entre corpo e escrita, performance e análise. "Dança" é postulado aqui como um "complexo sistema semântico, ou seja, um com 'significação' (Bedeutung)” apelando à uma "hermenêutica, a arte de compreender", o que evidentemente "não vale a pena para os debates teóricos" (CRAMER, 2003, p. 29-31). Assim " $a$ dança” acaba sendo postulada como forma notoriamente generalizada e como essência última do efêmero. Aqui não irei adentrar nem nos conteúdos e nas metodologias dessas questões que fazem parte de um debate que certamente não é novo, e nem na suposta oposição que é postulada pelos artigos publicados nessa revista entre o que seria "dança-dança" e 
"dança-conceito" (CRAMER, 2003, p. 30). O que fica evidente nessas contribuições que se identificam como "compreensões" da dança (da dança em geral, é notável que quase não se fala de danças específicas, singulares) que aqui ainda está sendo traçado um nítido divisor entre performance e contemplação, entre produção e interpretação.

\section{Seção: 3. Imagem}

Atendendo ao pedido de Gerhard Richter para sua instalação ACHT GRAU, o vidro opaco da janela da sala de exposição no Guggenheim de Berlim foi substituído por vidros transparentes (BUCHLOH, 2002, p. 19). Os painéis emailados de ACHT GRAU de Richter reiteram o formato dessas janelas. Eles refletem o espaço interior, os visitantes e também o espaço exterior mediado pelas janelas.

Um 'environment' que envolve o espectador: nessa implicação do que está do outro lado, as janelas e os espelhos opacos refletem o ponto cego da percepção e da compreensão; cito uma expressão de Gerhard Richter que data do ano 1996 sobre o vidro como símbolo: "ver tudo/compreender nada". ${ }^{4}$

Não está na hora já de dissolver esse grande divisor entre arte do evento e a ciência da descrição?

Já faz algum tempo que posições do teatro da vanguarda do século XX se despediram de um conceito de teatro segundo o qual o teatro era concebido como uma representação fechada, na qual um último significado (seja esse deus, o autor, um sentido definitivo) se duplica. Na teoria e nas diversas formas de performance surgiram modelos que implicam e envolvem o expectador na cena. De modo análogo, se difunde a fronteira entre o objeto da observação e a própria observação (observador e observado). A concepção de uma compreensão metódica e a possibilidade de totalização do sentido se tornou algo questionável, e isso repercute também nas 
questões referentes ao evento e registro. Deixamos para trás o conceito de compreensão e de análise que pressupõe uma identidade semântica do objeto (por exemplo, “a” dança).

Frente a isso, podemos destacar a imprecisão ${ }^{5}$ da percepção, que surge a partir das implicações do observador nesta zona cinza e intermediária de evento e registro e que não permite mais um claro divisor entre a observação participante e a perspectiva atenta à observação do observador. Com Roland Barthes poderíamos descrever esse fenômeno da diluição do divisor entre observador e performance, entre evento e os processos de registro como "sismologia"6: a desestabilização dos pontos de vista do observador, que se conjuga com a imprecisão do modo de ver o evento e o incontido do acontecer. Nesse sentido, a contingência da percepção e da memória no processo da observação e do ato posterior da descrição pode ser concebida como um fator da instabilidade e desestabilização da compreensão literal de registro. Barthes contrapõe a isso uma concepção gestual de registro, ou seja, uma mediada pelo corpo e guiada pelo movimento da mão chamando atenção para o ato de desenhar inerente ao registro como traço da escrita.

Seção: 4. Imagem

Cinza: uma polêmica com a mediação paradoxal de duas episteme da arte plástica que seriam aparentemente inconciliáveis - de um lado, a imagem como "janela transparente para o mundo", e, por outro lado, a "imagem como objeto opaco, como relevo monocromático [...]” (BUCHLOH, 2002, p. 14).

O que significa a constatação de uma imersão do observador no observado para uma teoria da relação entre evento e registro? Chego assim - novamente ao modo de um esboço - ao terceiro momento das minhas reflexões. 


\section{Evidência ou arte da ciência?}

De que modo a questão referente à "arte da Aufführung" afeta a teoria?

Dois aspectos me parecem especialmente relevantes na supracitada relação implicativa entre observador e acontecimento observado: de um lado, a virada da observação da estrutura para a produção de temporalização. Essa virada sempre está acompanhada por uma orientação no processo - uma orientação não apenas no caráter processual do "acontecer" observado, do evento, mas também na observação da temporalidade, seu adiamento e sua corrosão no trabalho de "re-construção" do registro. Só assim se pode articular como processo aquilo que se encontra numa junção da configuração do registro entre percepção contingente e memória fragmentada. Essa configuração é, por sua vez, ela mesma composta por diversas escalas de escritas e tempos. Ela desdobra em camadas sua própria performatividade, não mascarando-a (como ocorre nas análises hermenêuticas e semióticas tradicionais), mas, ao contrário, mostrando-a como forma específica de escrever, falar, conceber e realizar o registro. Trata-se de uma forma que não apenas assume sua temporalidade específica, mas que também torna visível sua proximidade e distância em relação ao evento, realizando assim o movimento de trans-posição sensível para o palco da teoria. ${ }^{7}$

Seção: 5. Imagem

ACHT GRAU. Monocromatismo e retirada estética

Grau, cinza - cito Gerhard Richter: “... Nas imagens cinzas há uma carência de diferenciação, nada, zero, o começo e o fim. Nos vidros estão as analogias com posições e possibilidades; nos painéis coloridos é o acaso, tudo é possível, ou antes: forma é non-sense" (RICHTER citado em BUCHLOH, 2002, p. 18).

Percepção da performance e a memória do registro interferem aí, onde a produção de evidência está em jogo. Trata-se certamente 
de modos distintos e formas de experiências diversas da evidência. A intercessão se mostra aí, onde a recepção sensível de um evento e sua performance é colocada num campo de coordenadas do registro, que passa a receber outra visibilidade: trata-se, nada menos, da 'evidentia' segundo a definição de Quintilian, ou seja, uma projeção de procedimentos marcados de tal modo, que cremos sermos mais capazes de vê-los que ouvi-los. ${ }^{8}$ Nesse sentido, a Aufzeichnung enquanto registro deveria desdobrar o seu potencial de tal correspondência de dar-a-ver como uma arte da descrição (ekphrasis). Como evidência no cenário da ciência, mas que não se esgota enquanto fixação da performance em estruturas, sistemas, tradições, códigos ou discursos, mas que reflete no palco da sua 'demonstratio' as condições de suas observações e incorpora as formas e brechas de suas convenções de percepção e representação no ato do registro.

Seção: 6. Imagem

ACHT GRAU - campos de reflexão monocromáticos

Um ato da separação de cor, campo e textura da pintura: aquilo, que antes era considerado como 'pintura', desenho e textura, desaparece nos campos de vidro de Richter. A imagem apenas adentra no espaço e processo de exposição através do expectador - como uma "aparição cinética e esquemática", como "sombra e reflexo" - e desaparece novamente, deixando para trás um "campo monocromático não marcado". ${ }^{9}$

Como poderia e deveria ser produzido no registro um momento desses da evidência como um ato correspondente à performance? Não há uma resposta para essa questão no sentido de um método ou uma regra aplicável. Desse modo, a evidência aparece como efeito desse processo do registro enquanto algo sempre já emergente - no sentido da definição (luhmanniana) de emergência como o surgir de algo que parece plausível retrospectivamente sem que antes tivesse sido previsível. ${ }^{10}$ Eis ao mesmo tempo uma verdadeira de- 
finição do criativo. Tal definição de emergência e a suposição de uma co-emergência de sujeito e objeto na ciência oferece ao mesmo tempo uma dimensão auto-reflexiva para a organização da ciência.

Uma possibilidade da produção dessa evidência como efeito emergente do registro seria incluir a corporalidade, ou seja, implicar o corpo no seu duplo papel enquanto agente e enquanto suporte material do processo de percepção e de registro no processo (de reflexão). Tratar-se-á, portanto, de conceber e por em marcha tal tentativa de uma arte do registro concebido como um empreendimento paradoxal: como modo de uma transcrição de performances, de algo fugaz, ou seja, de algo in-transponível, que não será fixado no registro, mas que inscreve um traço, que expõe o efêmero do registro como sendo uma característica intrínseca. Uma transcrição que finalmente deixa reconhecer que esse processo diferenciado da posterioridade do registro não compensa a perda do que sempre já é algo efêmero e passado da performance, mas que lhe dá (e retorna) algo!

Seção: 7.Imagem

ACHT GRAU: A construção dos painéis, o ajuste dos vidros monocromáticos mostra que os espelhos opacos não são campos de reflexão lisos, mas que são interrompidos pelos diferentes vínculos de inclinação, cada campo jogado em si. Assim o aparente ordenamento serial de elementos estáticos se torna um espaço genético de espelhos que variam e se movem entre si: não o estático e a hermenêutica do campo de vidro, do espelho - como aparece à primeira vista -, mas rotação, quebra da figura de reflexão.

E assim não acionamos também uma crítica da reflexão ela mesma? Como exposição e imersão especular do expectador?

\section{4. "Reescrita" ou Aufzeichnung como gesto}

Um registro de tal modo orientado para a produção de evidência deveria refletir sobre o paradoxo de sua própria estrutura e 
constituição e incorporá-lo no processo do registro: de um lado o ato de uma fixação dos momentos contingentes do evento como fixação transformativa, e, de outro lado, o ato da transposição ela mesma, como um ato corporal, material e medial, que seria por sua vez perceptível como um acontecimento performativo. Esse seria um processo da transcrição, no qual a escrita não seria mais concebida como aquilo que confere verdade contra a efemeridade e a impossibilidade da representação do evento, mas, ao contrário, no qual a escrita expõe a sua própria transitoriedade, colocando em risco assim o seu 'traço' como sendo um que é móvel e perecível. Destarte o registro ficaria absolvido de seu papel como compensação de uma perda, a saber, da perda de uma performance inevitavelmente transitória, que não pode ser trazida a tona novamente.

O experimento de tal teoria do registro, sua evidência como arte da ciência baseia-se assim na apresentação do próprio registro: como performance - e assim como um ato corporal que por sua vez também só se realiza na temporalidade de um movimento: como um 'gesto', tal como Giorgio Agamben o define. Pois o gesto, segundo Agamben, diz respeito a nada mais e nada menos que o estatuto da imagem do nosso tempo, na medida em que é através do gesto que a rigidez das imagens é suspendida e transportada para outro espaço como "imagens em movimento" (AGAMBEN, 2008, p. 12). O gesto, que está inscrita na "esfera da ação", é, segundo Agamben, " $a$ exibição de uma medialidade, o tornar visível um meio como tal. Este faz aparecer o ser-num-meio do homem [...]" (2008, p. 13). Nesse sentido vemos a potencialidade do rastro da escrita, da ação e paixão de escrever, de transpor e de traduzir tornando-se efetivo enquanto gesto: um agir e um mostrar que, no movimento da repetição, afeta o objeto mesmo da transcrição.

Seção: 8. Imagem

ACHT GRAU. "Vazio", "retirada da imagem", "manifesta falta de afetos" $"$ - eis os predicados atribuídos reiteradas vezes aos 
painéis de vidro de Gerhard Richter. Será que a experiência, a evidência do espaço de exposição, não está sempre já além? Num espaço de percepção da corporalidade diversificada e multiplicada, a abertura do possível?

Conceber a arte da Aufführung como arte da ciência não implica numa relação qualquer de equivalência postulada entre Aufführung e Aufzeichnung, evento e registro, original e tradução (que isso não seja mal compreendido). Ao contrário, trata-se de levar o observado a sério - mas também da ciência, ela mesma se mostrando nessa correspondência como sendo processual, que se daria num modo de olhar renovado e se renovando: como um olhar repetido, um "olhar como repetição". Não se trata nem de um momento demonstrativo e didático e nem de uma indicação para um método na análise de performance. Trata-se antes desse olhar que em cada ato de repetição se transforma, sendo concebido como uma prática e um agir da tradução como transposição, que faz com que a mediação desse processo - do gesto no sentido de Agamben - se torne o tema e ato de seu fazer e seu mostrar: numa exposição mútua que, como frisa, "is not stasis, but a simultaneous oscillation of potentiality in the act and of the act in potentiality" (AGAMBEN, 1992, p. 107).

Nesse sentido o registro de uma performance (por exemplo de uma dança) seria o gesto do gesto, pois, seguindo Agamben: "the gesture is a potentiality that does not realize itself in the act so as to be exhausted thereby but to preserve itself as potentiality in actions - and dance within it" (1992, p. 106). 


\section{Notas}

1. O texto "Zu einer Poetologie des Medienwechsel. Aufführung und Aufzeichnung - Kunst der Wissenschaft?" foi publicado em Erika Fischer-Lichte, Clemens Risi e Jens Roselt (org.): Kunst der Aufführung.Aufführung der Kunst, Theater der Zeit, Recherchen 18, Berlin 2004, p. 40-50. Uma versão reduzida deste texto foi publicado em inglês sob o título: "Preserving the Performance: Scholarhip as Art”, Performance Reaearch, 11:2, 15-23.

2. Tempus naquele sentido definido por Harald Weinrich como uma forma de "mundo narrado" e de "encenação narrativa" (cf. WEINRICH, 1994).

3. Cf. Revista Ballettanz 3/2003.

4. Em GUGGENHEIM FOUNDATION (org.) Gerhard Richter: ACHT GRAU. New York, 2002, p. 9.

5. No sentido em que o tema da imprecisão foi definido em ULLRICH (2002) e em WILDGRUBER (2000).

6. Roland Barthes citado em NEUMANN (2000, p. 68).

7. Seguindo a acepção de uma "agência" (Agentur) da interpretação a lógica não é mais reconhecível (apenas) no paradigma da escrita, mas como o lado performativo de uma prática: como um modo de agência para a produção de evidência (cf. PETERS, 2003).

8. Cf. Quintilian no verbete 'Evidentia, Evidenz' em UEDING (1996, p.37-47), em particular onde se lê: "já não se passa mais como se as coisas fossem narradas, mas como se elas mesmas fossem encenadas" (1996, p. 44).

9. Em GUGGENHEIM FOUNDATION (org.) Gerhard Richter: ACHT GRAU. New York, 2002, p. 19-20. 
10. No sentido de Hans Ulrich Gumbrecht, John Bravman, Andrew Milne et al, Emergence. A manifesto for risk taking interdisciplinarity, 2002 (documento não publicado e repassado para Gabriele Brandstetter).

11. Em GUGGENHEIM FOUNDATION (org.) Gerhard Richter: ACHT GRAU. New York, 2002, p. 16.

\section{Bibliografia}

AGAMBEN, G. (2008): Notas sobre o gesto. Artefilosofia, n.4, Ouro Preto, jan. . (2000): Notes on Gesture (1992). In: Means without Ends: Notes on Politics. Minneapolis and London: University of Minnesota Press, p. 49-60.

. (1992): Noten zur Geste. In: GEORG-LAUER, Jutta (org.) Postmoderne und Politik. Tübingen.

BORMANN, H. (2004): Theatralität als Vorschrift. Zu Michael Frieds Kunst und Objekthaftigkeit. In: FISCHER-LICHTE, Erika, HORN, Christian, UMATHUM, Sandra \& WARSTAT, Matthias (org.) Diskurse des Theatralen. Basel: Theatralität 7 .

BUCHLOH, B. (2002): Gerhard Richters ACHT GRAU: zwischen Vorschein und Glanz. In: GUGGENHEIM FOUNDATION (org.) Gerhard Richter: ACHT GRAU. New York, p. 13-29.

CRAMER, F.A. (2003): Wie darf ich Tanz verstehen? In: Ballettanz 3/2003, p. 28-31. 
GUMBRECHT, H. U. (2001): Produktion von Präsenz, durchsetzt mit Absenz. Über Musik, Libretto und Inszenierung. In: FRÜCHTL, Josef \& ZIMMERMANN, Jörg (org.) Ästhetik der Inszenierung. Frankfurt a. M.: Suhrkam, p. 63-76.

GUGGENHEIM FOUNDATION (org.) (2002): Gerhard Richter: ACHT GRAU. New York: The Solomon R. Guggenheim Foundation.

NEUMANN, G. (2000): Theatralität der Zeichen. In: NEUMANN, Gerhard, PROSS, Caroline \& WILDGRUBER, Gerald (org.). Szenographien. Theatralität als Kategorie der Literaturwissenschaft. Freiburg i.Br.: Rombach Wissenschaften/Litterae 78, p. 65-112.

PETERS, S. (2003): Performative Writing 1800/2000? Evidenz und Performanz in der medialen Refiguration des Wissens. In: FISCHER-LICHTE, Erika, HORN, Christian, UMATHUM, Sandra \& WARSTAT, Matthias (org.) Performativität und Ereignis. Tübingen/Basel: Theatralität 4.

SEEL, M. (2001): Inszenierung als Erscheinenlassen. Thesen über die Reichweite eines Begriffs. Em FRÜCHTL, Josef \& ZIMMERMANN, Jörg (org.) Ästhetik der Inszenierung. Frankfurt a. M.: Suhrkamp, p. 48-62.

Recebido em 30/05/2012

Aceito em 25/10/2012 